\title{
LOSSES, EFFICIENCY AND THERMAL BEHAVIOR OF THE SYNCHRONOUS MOTORS WITH DIFFERENT PM MATERIALS
}

The paper deals with losses, efficiency and thermal behavior of the synchronous machines with different permanent magnet (PM) materials. Three PMSM are presented in this paper: First, the PMSM with NdFeB PM, which is really constructed. Second, the NdFeB was replaced by ferrites PM. Third, the new design of synchronous motor with ferrites is presented. The volume of PM and the whole size are increased to keep the same power output. Equivalent circuit parameters, EMF, V-curves, losses, efficiency and thermal behavior of all three machines are investigated and compared.

Keywords: NdFeB, ferrite, synchronous motor, efficiency, thermal behavior, $V$ - curves.

\section{Introduction}

Thanks to new PM materials with high energy product, such as $\mathrm{NdFeB}$ the synchronous motor with PM (PMSM) can be a very good choice for many industrial applications. Nowadays (2012) the cost of this type of PM has enormously increased. This situation forces the electric machine producers to restrict the PMSM production or to look for other PM materials such as Alnico alloys or ferrites, the main properties of which are shown in Table 1.

PM materials properties [1] and [2]

Table 1.

\begin{tabular}{|c|c|c|c|c|}
\hline & $\mathrm{BH}_{\max }\left(\mathrm{kJm}^{-3}\right)$ & $\mathrm{B}_{\mathrm{r}}(\mathrm{T})$ & $\mathrm{H}_{\mathrm{c}}\left(\mathrm{kAm}^{-1}\right)$ & $\rho_{\mathrm{PM}}(\Omega \mathrm{cm})$ \\
\hline $\mathrm{NdFeB}$ & $220-500$ & $0.97-1.45$ & $740-1000$ & $100-200 \cdot 10^{-6}$ \\
\hline SmCo & $120-240$ & $0.85-1.1$ & $620-840$ & $86 \cdot 10^{-6}$ \\
\hline Ferrite & $7-42$ & $0.2-0.48$ & $120-360$ & $10^{6}$ \\
\hline Alnico & $10-35$ & $0.6-1.16$ & $40-120$ & $47-68 \cdot 10^{-6}$ \\
\hline
\end{tabular}

It is interesting to compare properties of motors with various kinds of PM materials.

In [3] the authors investigated two PMSMs. One is with ferrite magnets and another is with $\mathrm{NdFeB}$ magnets. Both of them are interior type so the PMs are totally embedded in rotor. The authors did complete analysis of parameters, losses and efficiencies of both motors. The efficiency of a ferrite motor was about $1 \%$ lower than in a motor with $\mathrm{NdFeB}$ if the volume of ferrites was five times higher than the volume of $\mathrm{NdFeB}$.
In [4] the authors presented two PMSMs. One is with SmCo magnets and another is with ferrites. The efficiency of the ferrite motor was by $0.5 \%$ lower at the same output power. The weight of ferrites increased 2.5 times in comparison with $\mathrm{SmCo}$

In [5] the authors presented PMSM with ferrites and with damper winding. The authors compare their machine with another at the constant PM volume. PMSM with ferrites shows $4 \%$ improvement in efficiency.

This paper deals with synchronous motors with two kinds of PM materials. First, the original PMSM with NdFeB is presented (motor A). Second, the NdFeB is replaced by ferrite in the original PMSM construction (motor B), see Fig. 1. Third, the new design of PMSM with ferrites is presented (motor C), see Fig. 2. All three motors are investigated with regard to efficiency and thermal behavior.

\section{PMSMS configurations and parameters}

Permanent magnets of Motor A and B are totally immersed in rotor, which means they are interior type of the PMSM. Motor $\mathrm{C}$ has surface mounted magnets which provides higher magnetic flux density into the air gap. The aim was to achieve the same output power as in the case of Motor A. The parameters and dimensions of all three motors are in Table 2.

The motor $\mathrm{C}$ has bigger dimensions and PMs volume due to lower energy product of ferrite PMs. The parameters of PM materials used in the investigation of all motors are presented in Table 3.

\footnotetext{
* Peter Sekerak, Valeria Hrabovcova, Matus Onufer, Pavol Rafajdus, Lukas Kalamen

University of Zilina, Department of Power Electrical Systems, Zilina, Slovakia, E-mail: valeria.hrabovcova@fel.uniza.sk
} 


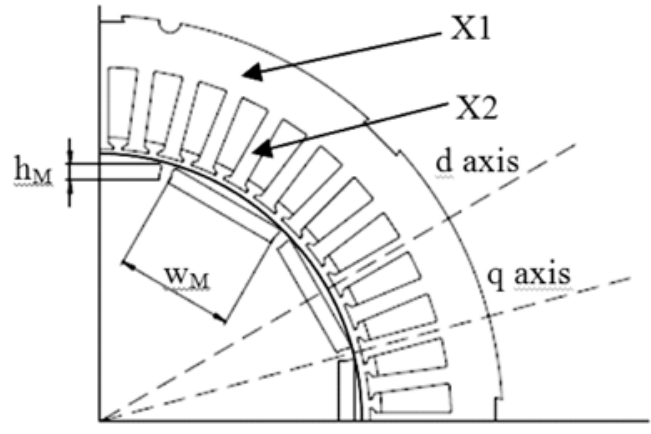

Fig. 1 Cross section area of a quarter of Motor A,B

a)
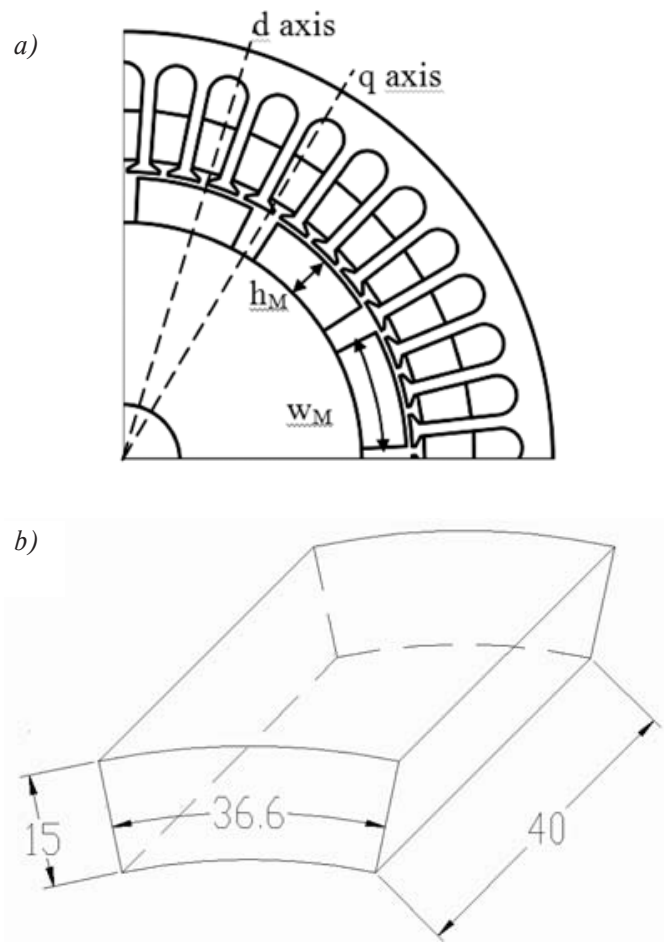

Fig. 2 a) Cross section area of a quarter of Motor $C$ b) detail of PM shape

On the basis of analytical calculations and FEM simulations [6] the parameters of all three models were investigated. The parameters such as stator resistance $R_{s}$, stator leakage inductance $L_{\sigma}$, magnetizing inductance in $d$ and $q$ axis $L_{\mu d}, L_{\mu q}$ and flux linkage established by PMs $\psi_{P M}$ are shown in Table 4.

\section{PMSM properties}

First, the PM electromotive force $E_{P M}$ is studied. Its value has significant influence on all properties. Then the $\mathrm{V}$-curves were investigated. They show an optimal operating point with minimal
Parameters and dimension of Motor A, B and C

Table 2.

\begin{tabular}{|l|c|c|c|}
\hline Parameter & Motor A & Motor B & Motor C \\
\hline PM material & NdFeB & ferrite & ferrite \\
\hline Stator phase voltage & $230 \mathrm{~V}$ & $230 \mathrm{~V}$ & $230 \mathrm{~V}$ \\
\hline Frequency & $36 \mathrm{~Hz}$ & $36 \mathrm{~Hz}$ & $36 \mathrm{~Hz}$ \\
\hline Pole pairs & 6 & 6 & 6 \\
\hline Rated power & $2 \mathrm{~kW}$ & $0.5 \mathrm{~kW}$ & $2 \mathrm{~kW}$ \\
\hline Outer rotor diameter & $0.146 \mathrm{~m}$ & $0.146 \mathrm{~m}$ & $0.19 \mathrm{~m}$ \\
\hline Outer stator diameter & $0.22 \mathrm{~m}$ & $0.22 \mathrm{~m}$ & $0.288 \mathrm{~m}$ \\
\hline Iron stack length & $0.14 \mathrm{~m}$ & $0.14 \mathrm{~m}$ & $0.12 \mathrm{~m}$ \\
\hline Permanent magnet width & $4 \mathrm{~mm}$ & $4 \mathrm{~mm}$ & $15 \mathrm{~mm}$ \\
\hline Permanent magnet length & $32 \mathrm{~mm}$ & $32 \mathrm{~mm}$ & $36.6 \mathrm{~mm}$ \\
\hline PMs volume & $215 \mathrm{~cm}^{3}$ & $215 \mathrm{~cm}^{3}$ & $794 \mathrm{~cm}^{3}$ \\
\hline Stator winding turns & 420 & 420 & 840 \\
\hline Stator slots & 48 & 48 & 45 \\
\hline Slots per pole & 4 & 4 & 3.75 \\
\hline Slots per pole per phase & 1.33 & 1.33 & 1.25 \\
\hline
\end{tabular}

* at Motor B it is power at rated current

PM materials properties [1] and [2]

Table 3 .

\begin{tabular}{|c|c|c|}
\hline \multicolumn{3}{|c|}{ NdFeB } \\
\hline $\mathrm{Br}$ & $\mathrm{Hc}$ & $\mathrm{BHmax}$ \\
\hline $1.15 \mathrm{~T}$ & $860 \mathrm{kAm}^{-1}$ & $240 \mathrm{kJm}^{-3}$ \\
\hline \multicolumn{3}{|c|}{ Ferrite } \\
\hline $\mathrm{Br}$ & $\mathrm{Hc}$ & $\mathrm{BHmax}$ \\
\hline $0.45 \mathrm{~T}$ & $340 \mathrm{kAm}^{-1}$ & $40 \mathrm{kJm}^{-3}$ \\
\hline
\end{tabular}

PMSM parameters

Table 4.

\begin{tabular}{|c|c|c|c|}
\hline & Motor A & Motor B & Motor C \\
\hline$R_{s}$ & $3.93 \Omega$ & $3.93 \Omega$ & $6.047 \Omega$ \\
\hline$L_{\sigma}$ & $0.0289 \mathrm{H}$ & $0.0289 \mathrm{H}$ & 0.0933 \\
\hline$L_{\mu d}$ & $0.025 \mathrm{H}$ & $0.025 \mathrm{H}$ & $0.0297 \mathrm{H}$ \\
\hline$L_{\mu q}$ & $0.078 \mathrm{H}$ & $0.078 \mathrm{H}$ & $0.0297 \mathrm{H}$ \\
\hline$\psi_{P M}$ & $0.828 \mathrm{Vs}$ & $0.2 \mathrm{Vs}$ & $1.325 \mathrm{Vs}$ \\
\hline$E_{P M}$ & $132.5 \mathrm{~V}$ & $34 \mathrm{~V}$ & $211 \mathrm{~V}$ \\
\hline$U_{s p h} / E_{P M}$ & 1.73 & 6.76 & 1.09 \\
\hline
\end{tabular}

current and, consequently, with minimal value of Joule losses. Also thermal behavior of all motors was searched.

\section{A. $E_{P M}$}

$E_{P M}$ is a very important parameter for PMSM operation. The ratio of the stator phase voltage $U_{s p h}$ over $E_{P M}$ is defined. A very 
high ratio of the $U_{s p h} / E_{P M}$ means a big difference between the induced and terminal voltage which results in a high stator current $I_{a s}=\left(U_{s p h}-E_{P M}\right) / X_{d}$. This is a base for high Joule losses.

The waveform of the air gap magnetic flux densities $B_{\delta}$ of Motors A, B and C are depicted in Figs. 3 a, b, c. Note a great difference in $B_{\delta}$ values of Motor B and its low fundamental harmonic in Fig. 4 where the Fourier series of $B_{\delta}$ of all the motors are shown.


c)

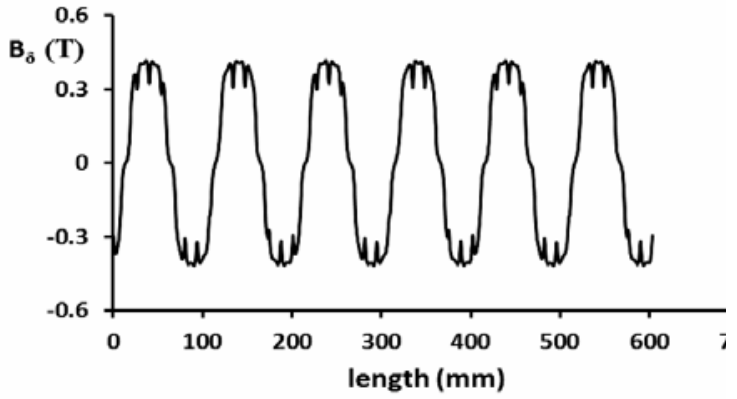

Fig. 3 Air-gap magnetic flux density of a) Motor A b) Motor B c) Motor $C$ versus the whole air gap periphery (12 poles)

The induced voltage $E_{P M}$ created in the stator winding by PM can be calculated for each $v$ harmonic component by the formula

$$
E_{P M \nu}=\sqrt{2} \pi f_{\nu} \phi_{\nu} N k_{w \nu},
$$

where $f_{v}$ is the frequency, $N$ is the number of stator winding turns, $k_{w v}$ is its winding factor and $\phi_{v}$ is the magnetic flux calculated by



Fig. 4 Fourier series of air gap magnetic flux densities of Motors A, B and C

$$
\phi_{\nu}=\frac{2}{\pi} B_{\delta \nu} \frac{\tau_{p}}{\nu} l_{F e}
$$

where $l_{F e}$ is the iron stack length, $\tau_{p}$ is the pole pitch.

Fig. 5a shows the simulated induced phase voltage of Motor A gained by means of FEM and calculated by the sum of $E_{P M_{v}}(1)$. In Fig. $5 \mathrm{~b}$ is shown a real measured waveform of phase voltage of Motor A taken by an oscilloscope. The coincidence of measured and simulated waveforms is very good. This means that this procedure is applicable for Motors B and C. The RMS value of $E_{P M}$ of Motor A is $132.5 \mathrm{~V}$, Table 4. Ratio $U_{s p h} / E_{P M}$ is 1.73 at $U_{s p h}=230 \mathrm{~V}$.

a)



a)

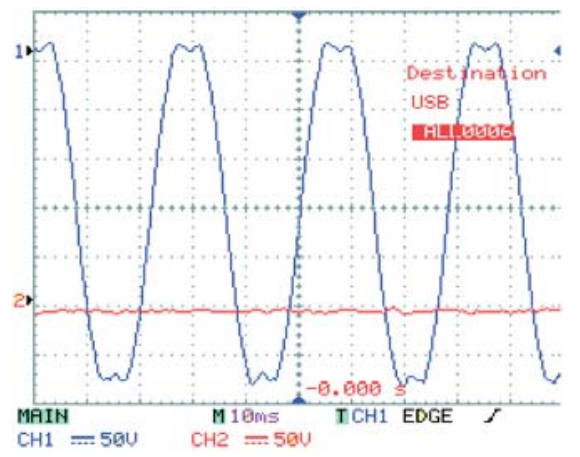

Fig. $5 E_{P M}$ waveform of Motor $A$ a) simulated by means of FEM and calculated by (1), b) measured 
The simulated $E_{P M}$ of Motor B is shown in Fig. 6.

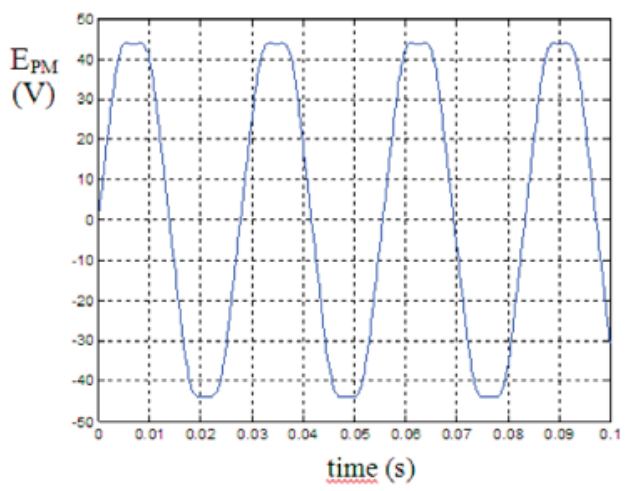

Fig. $6 E_{P M}$ waveform of Motor $B$ - simulated by means of FEM

The simulated $E_{P M}$ of Motor $\mathrm{C}$ is shown in Fig. 7.



Fig. $7 E_{P M}$ waveform of Motor $C$ - simulated by means of FEM

The RMS value of induced voltage $E_{P M}$ of Motor B is $E_{P M r m s}=$ $=34 \mathrm{~V}$, see Table IV. This value gives the ratio $U_{\text {sph }} / E_{P M}=6.76$ at $U_{s p h}=230 \mathrm{~V}$. In comparison with Motors $\mathrm{A}$ and $\mathrm{C}$ is this value enormously low because of its very low remanent magnetic flux density. Motor $\mathrm{C}$ gives $E_{\text {PMrms }}=211 \mathrm{~V}$, see Table 4 . The ratio $U_{s p h} / E_{P M}$ is 1.09 at $U_{s p h}=230 \mathrm{~V}$. This ratio is very close to theoretically recommended $U_{s p h} / E_{P M}=1.11$. These values and motors parameters will be put into the simulation model to determine their properties.

\section{B. $\quad V$ - curves}

The $\mathrm{V}$ - curves in the case of PM excitation, which is constant, can be plotted as stator current $I_{a s}$ versus ratio of $U_{s p h} / E_{P M}$ at different loads. Fig. 8 shows $\mathrm{V}$ - curves of Motor A. The simulations were verified by experiments. The stator voltage was changed from $230 \mathrm{~V}$ to $150 \mathrm{~V}$ which represents ratio $U_{s p h} / E_{P M}$ from 1.73 to 1.13 respectively. The motor was loaded from $1 \mathrm{~kW}$ to $2.5 \mathrm{~kW}$. The results of simulation and experiments are in good coincidence.
$\mathrm{V}$ - curves show the optimal operational point in their minimum. Also the minimal current $I_{a s}$ and corresponding ratio $U_{s p h} / E_{P M}$ at the given power can be seen.

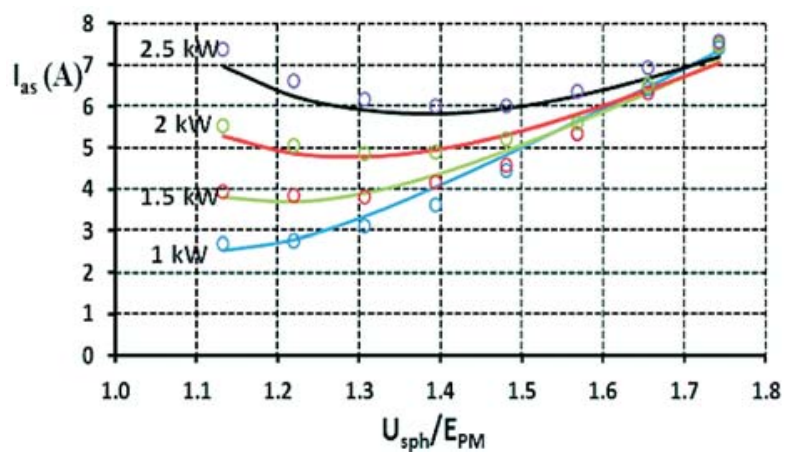

Fig. $8 \mathrm{~V}$ - curves of Motor A at frequency $36 \mathrm{~Hz}$. Lines represent simulated data, circles measured data

Fig. 9 shows V - curves of Motor B. Motor B was loaded, in simulation only, by loads $0.5 \mathrm{~kW}, 1 \mathrm{~kW}, 1.5 \mathrm{~kW}, 2 \mathrm{~kW}$ and $2.5 \mathrm{~kW}$. The stator voltage was changed from $230 \mathrm{~V}$ to $116 \mathrm{~V}$ which means ratio $U_{s p h} / E_{P M}$ from 6.8 to 3.4 respectively. As it is seen from Fig. 9 Motor B can provide $2 \mathrm{~kW}$, but in comparison with other two motors mentioned above the stator current $I_{a s}$ is very high (around $10 \mathrm{~A}$ ). The ratio $U_{s p h} / E_{P M}$ is very high and it doesn't meet the requirement for optimal ratio $U_{s p h} / E_{P M}=1.11$ [7]. A solution could be its operation at lower stator terminal voltage to achieve a ratio of $U_{s p h} / E_{P M}$ closer to 1.11 . In that case for $E_{P M}=34 \mathrm{~V}$ the $U_{\text {sph }}$ should be around $38 \mathrm{~V}$. This would result in power around 50 W. It means that Motor B cannot operate satisfactorily in the required range of powers and stator voltage.

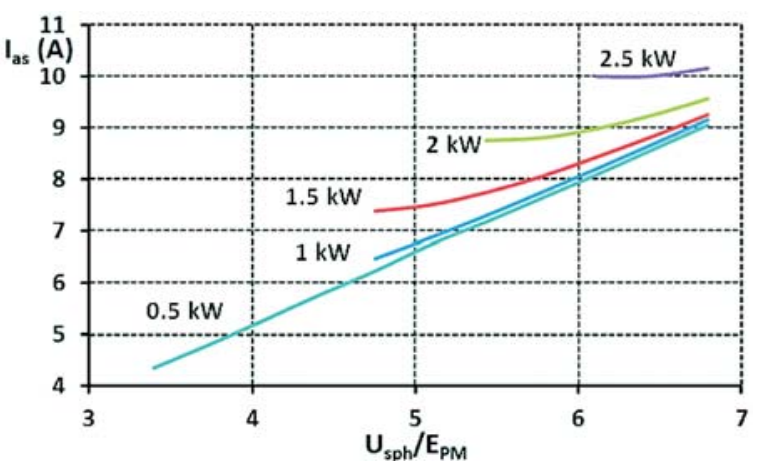

Fig. $9 \mathrm{~V}$ - curves of Motor B at frequency $36 \mathrm{~Hz}$

The $\mathrm{V}$ - curves of Motor $\mathrm{C}$ are shown in Fig. 10. The stator voltage was changed from $266 \mathrm{~V}$ to $175 \mathrm{~V}$, which represents the ratio $U_{s p h} / E_{P M}$ from 1.26 to 0.82 , respectively. At $2 \mathrm{~kW}$, the 
minimum of stator current $3.15 \mathrm{~A}$ is achieved at $U_{s p h} / E_{P M}=1.16$ which is very close to the recommended value 1.11.

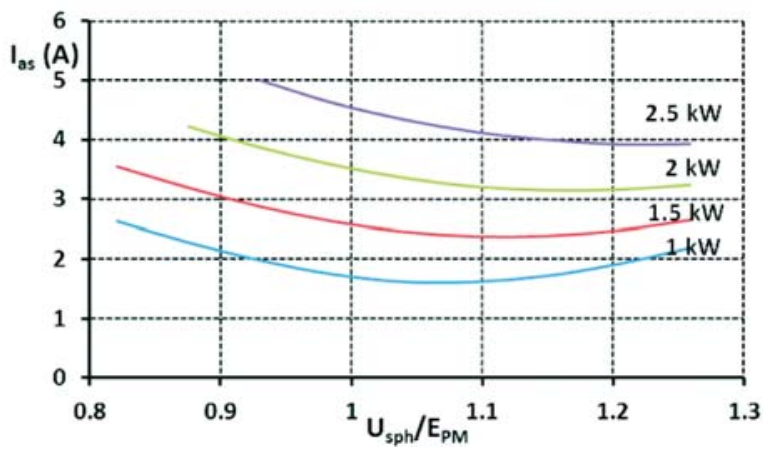

Fig. $10 \mathrm{~V}$ - curves of Motor C at frequency $36 \mathrm{~Hz}$

\section{Losses}

Losses were investigated in all three motors. The next types of losses were taken into account:

- Joule losses $\Delta P_{J}$

- Iron losses $\Delta P_{\text {iron }}$

- PM losses $\Delta P_{P M}$

- Mechanical losses $\Delta P_{\text {mech }}$

- Additional losses $\Delta P_{a d}$

The Joule losses are calculated by:

$$
\Delta P_{J}=3 R_{s p h} I_{a s}^{2}
$$

where $R_{s p h}$ is the phase resistance at $75^{\circ} \mathrm{C}$.

Iron losses in n-th element (element means tooth, yoke, etc.) were calculated by the following formula [7]:

$$
\Delta P_{i r o n, n}=p_{10}\left(\frac{B_{\max , n}}{1 T}\right)^{2} m_{i r o n, n}\left(\frac{f}{50}\right)^{1.3}
$$

where $p_{10}=3.1 \mathrm{Wkg}^{-1}$ is the iron loss per unit of mass at magnetic flux density $B=1 \mathrm{~T}, B_{\max , n}$ is the amplitude of magnetic flux density in $n$-th element of the machine and $m_{\text {iron, } n}$ is its mass. The investigation of magnetic flux densities was done by means of FEM.

The amplitude of magnetic flux density $B_{\max , n}$ has two components, tangential and normal as can be seen in Fig. 11.

$$
B_{\text {max }, n}=\sqrt{B_{\text {max }, n \text { tan }}^{2}+B_{\text {max }, n, n o r m}^{2}}
$$

The waveforms of tangential and normal components of the magnetic flux density versus electrical angle of the stator inner periphery of Motor A at the output power $2 \mathrm{~kW}$ and optimal $U_{s p h} / E_{P M}=1.27$ is shown in Figs. 12a,b. These values are taken from Fig. 1, point X1, in the stator yoke, and X2, in the stator tooth.

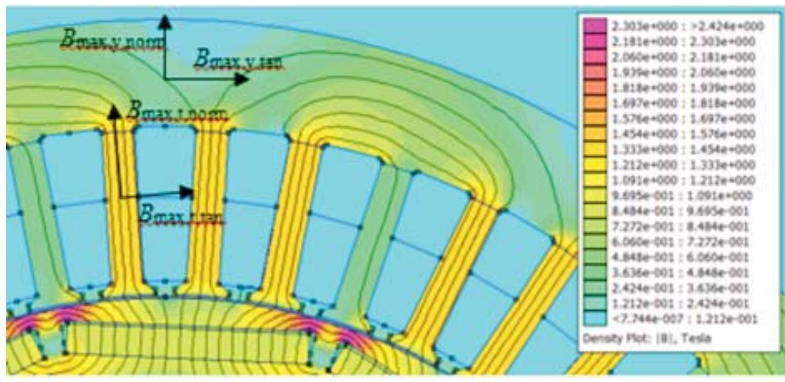

Fig. 11 Cross section PMSM with marked normal and tangential components of the magnetic flux density



a)

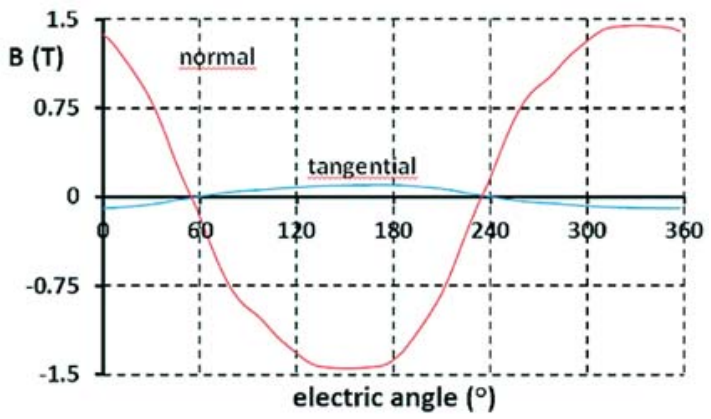

b)

Fig. 12 The tangencial and normal components of magnetic flux density in a) stator yoke,

b) stator tooth of Motor A at rated load and optimal $U_{\text {sph }} / E_{P M}=1.27$

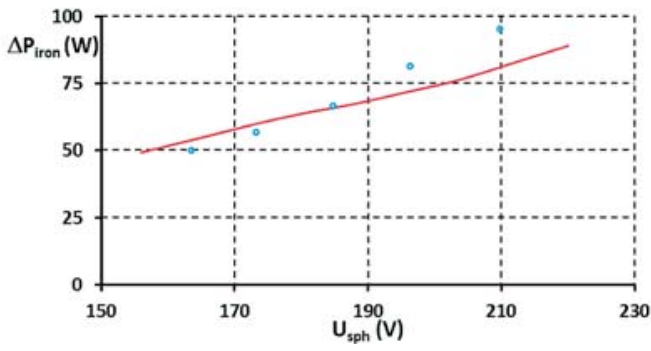

Fig. 13 The iron losses of Motor A versus stator voltage at $500 \mathrm{rpm}$

The line represents simulated data, circles experimental data 
On the basis of (4) and (5) the iron losses were calculated and compared with the experimental data, see Fig. 13.

The experimental data were gained by measurements where the input phase stator voltage was gradually changed (see Fig. 13) and current, input power, output power and temperature were measured. The total input power is expressed as:

$$
\begin{aligned}
& P_{\text {in }}=P_{\text {out }}+\Delta P_{j s}+\Delta P_{\text {iron }}+\Delta P_{a d}+\Delta P_{P M}+\Delta P_{\text {mech }}= \\
& =P_{\text {out }}+\Delta P
\end{aligned}
$$

It is clear that to evaluate together the $\Delta P_{\text {iron }}+\Delta P_{a d}$ from the $\Delta P$, it is necessary to subtract the components of $\Delta P_{j s}, \Delta P_{P M}$, and $\Delta P_{\text {mech }}$. Joule losses $\Delta P_{j s}$ were corrected by temperature to involve the changing of the stator resistance. The mechanical losses $\Delta P_{\text {mech }}=$ $=51 \mathrm{~W}$ at $500 \mathrm{rpm}$ were determined by special measurement. Losses in PM were finally neglected, see (7), (8). This approach was accepted in simulation as well as in measurement evaluation. The measurement was carried out at sinusoidal voltage and frequency of $50 \mathrm{~Hz}$.

The simulated iron losses as a function of stator phase voltage of Motor B and C are shown in Fig. 14



Fig. 14 The simulated iron losses of Motors $B$ an $C$

The PM losses were calculated on the base of Ruoho at al. [8], where the next expression is given:

$$
\Delta P_{P M}=\frac{V_{P M} f^{2} w_{P M}^{2} B_{P M}^{2}}{12 \rho}
$$

The $w_{P M}$ is the PM width, $\rho=150 \cdot 10^{-6} \Omega \mathrm{cm}$ is the resistivity of the NdFeB PM and $B_{P M}$ is a magnitude of $B$ pulsation in permanent magnet. If the PM volume $V_{P M}$ is substituted by $w_{P M} l_{P M} h_{P M}$, it is seen that eddy current loss in PM depends on the 3rd power of the PM width. This model neglects the eddy current loss on the edge of the magnets. If this kind of the eddy current loss should be taken into account than the next formula must be used:

$$
\Delta P_{P M}=\frac{f^{2} B_{P M}^{2}}{16 \rho} \frac{w_{P M}^{3} l_{P M}^{3} h_{P M}}{\left(w_{P M}^{2}+l_{P M}^{2}\right)}
$$

where $l_{P M}$ is the PM length in the axial direction and $h_{P M}$ is the PM height in the radial direction.
The PM loss was investigated by simulation by means of $2 \mathrm{D}$ FEM, [9]. The dashed red line on the PM surface represents the place where magnetic flux density was investigated, see Fig. 15.



Fig. 15 FEM model for investigation of magnetic flux density on the PM surface (see dashed red line)

The 2D FEM model represented the no-load condition in a generating mode. In this mode the influence of the stator slots could be seen on the magnetic flux density taken on the PM surface. However, this phenomenon is clear only in the case of the surface mounted PM. In the investigated motor the PMs are immersed in the rotor body and no influence of the stator slots can be observed. This is clearly seen in Fig. 16 where the smooth waveform of the magnetic flux density on the PM surface along the PM width is presented.

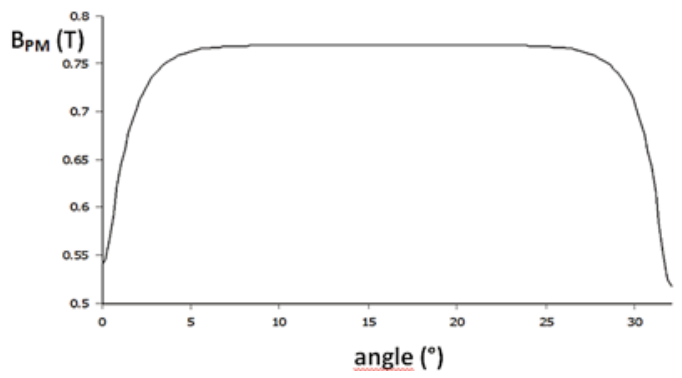

Fig. 16 The waveform of the magnetic flux density on the PM surface versus PM width in generating no-load condition (Motor A)

In the next step the simulation of the loaded motoring condition at rated $53 \mathrm{Nm}$ was carried out. The profile of the air gap magnetic flux density along the rotor periphery, where the influence of the stator slots can be seen, is in Fig. 17a, the profile of the magnetic flux density investigated on the PM surface, if the PMSM is loaded, is in Fig. 17b. It is seen that the waveform is distorted by armature reaction in comparison with no load condition (Fig. 16).

The waveform of the $B_{P M}$ from Fig. $17 \mathrm{~b}$ was kept constant which means no variation in time and as a consequence no eddy currents in the PM. It means that the immerse PMs in the rotor 




a)

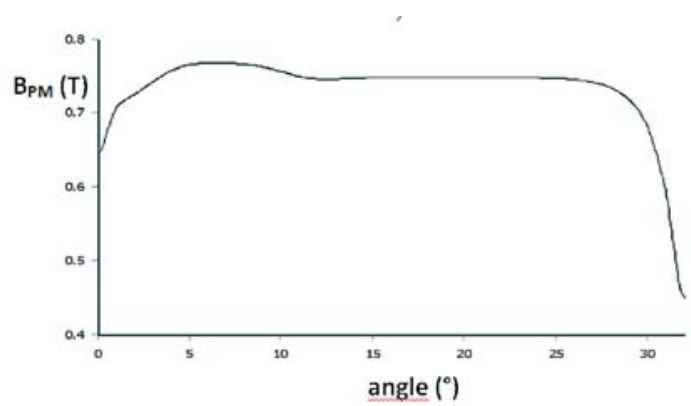

b)

Fig. 17 Magnetic flux density versus air gap periphery: a) in the air gap of the PMSM, b) on the surface of the immersed PM if PMSM was loaded by the rated torque $53 \mathrm{Nm}$

body are shielded by a layer of iron over them and protected against the influence of the stator slotting. Therefore, no eddy currents in PMs can be observed in this case and the losses in the PMs can be neglected.

In motor $\mathrm{C}$ where ferrites are employed and they are mounted on the surface of the rotor, the PM losses can be also neglected but due to another reason.

The ferrites have very high resistivity, $10^{6} \Omega \mathrm{cm}$, see Table 1 , which is much more higher than in NdFeB PMs. This fact considerably affects their operational performances in a positive way.

Mechanical losses were measured and calculated by empirical formulas by [7]. For Motors A and B the $\Delta P_{\text {mech }}$ is $36 \mathrm{~W}$ and for Motor $\mathrm{C} \Delta P_{\text {mech }}$ is $40 \mathrm{~W}$ at $360 \mathrm{rpm}$.

\section{Efficiency}

The operation at the optimal stator current will result in lower winding losses and higher efficiency. The comparison of all three motor types can be done on the base of Figs. 18, 19 and 20.

Efficiency was calculated by a well known formula:

$$
\eta=\frac{P_{\text {out }}}{P_{\text {in }}}=\frac{P_{\text {out }}}{P_{\text {out }}+\Delta P_{j s}+\Delta P_{\text {iron }}+\Delta P_{\text {ad }}+\Delta P_{\text {mech }}}
$$

Motor A was simulated and really measured, Motors B and C were investigated by simulations only. Fig. 18 shows the efficiency of Motor A at different loads. Into the simulations the Joule losses, iron losses simulated by 2D FEM models and the mechanical losses were introduced.

The maximal efficiency of Motor A $\eta=86.5 \%$ at rated load was achieved at ratio $U_{s p h} / E_{P M}=1.33$, see Fig. 18 .



Fig. 18 The efficiency of Motor A, Lines represent simulated data, circles represent measurements.

Fig. 19 shows the efficiency of Motor B at different loads, Fig. 20 the Motor C.

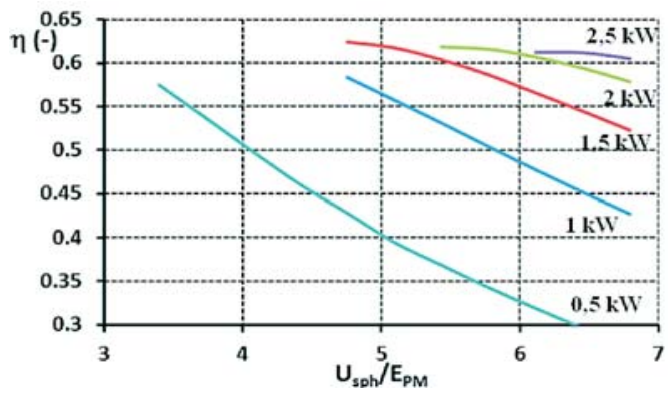

Fig. 19 Efficiency of Motor B

Motors A and C, see Figs. 18 and 20, provide good efficiency. The efficiency of motor B (Fig. 19) is very low, which doesn't match the requirements of high efficiency industrial applications. If the design of the PMSM with ferrites is changed appropriately as it was done in motor $\mathrm{C}$, the efficiency is comparable with the PMSM with $\mathrm{NdFeB}$ magnets: the maximal efficiency of motor $\mathrm{C}$ is $\eta=87.5 \%$ at ratio $U_{s p h} / E_{P M}=1.16$.

\section{E. Thermal behavior}

An investigation of thermal behavior of electric motors is very important because of PM and insulation of the stator winding. The stator winding insulation has a temperature limit of $155^{\circ} \mathrm{C}$ which belongs to thermal class $\mathrm{F}$. The $\mathrm{NdFeB} \mathrm{PM}$ have maximal allowed working temperature around $120{ }^{\circ} \mathrm{C}$. In order not to exceed it, the thermal measurement and thermal simulation was carried out by means of a thermal equivalent circuit and equation 


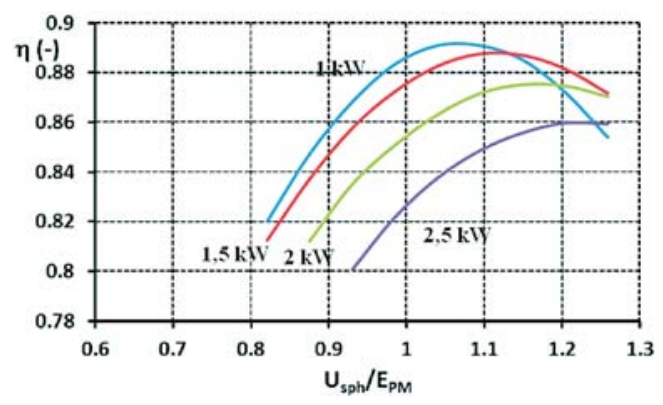

Fig. 20 Efficiency of Motor C

system by means of Matlab. In Motor A the simulations were confirmed by the experiments. The temperature curves are plotted in Fig. 21. The experiments and simulations were performed for the rated load $2 \mathrm{~kW}$ and for two values of the stator voltages. At the rated stator voltage $230 \mathrm{~V}$ the temperature exceeds the allowed values of $155^{\circ} \mathrm{C}$ (class $\mathrm{F}$ ) in the stator winding as well as $120^{\circ} \mathrm{C}$ in PM. Then such stator voltage, at which the stator current is the smallest one $\left(I_{a s}=4.9 \mathrm{~A}\right)$, see Fig. 8, was applied. The ratio is $U_{s p h} / E_{P M}=1.27$, which gives $U_{s p h}=180 \mathrm{~V}$. In this operating point



a)

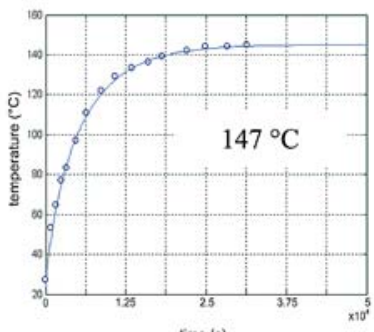

c)



b)

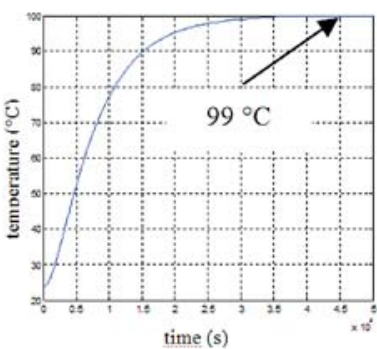

d)
Fig. 21 The temperature curves of Motor A for rated load $2 \mathrm{~kW}$ : a) stator winding temperature, $U_{s p h}=230 \mathrm{~V}, I_{a s}=7.3 \mathrm{~A}$,

b) $P M$ temperature, $U_{s p h}=230 \mathrm{~V}, I_{a s}=7.3 \mathrm{~A}, \mathrm{c}$ ) stator winding temperature, $U_{\text {sph }}=180 \mathrm{~V}, I_{a s}=4.9 \mathrm{~A}$,

d) PM temperature, $U_{s p h}=180 \mathrm{~V}, I_{a s}=4.9 \mathrm{~A}$. Lines represent simulated data, circles represent experimental data the Joule losses should be the smallest and also temperature is the smallest but it is close to the temperature limit (see Figs. $21 \mathrm{c}, \mathrm{d}$ ).

The Motor $\mathrm{C}$ operates at the rated load $2 \mathrm{~kW}$ very close to the optimal smallest stator current. At this point the $U_{s p h} / E_{P M}$ is 1.09 , which means $U_{s p h}=230 \mathrm{~V}$. The simulation was carried out in this operating point, see Fig. 22.

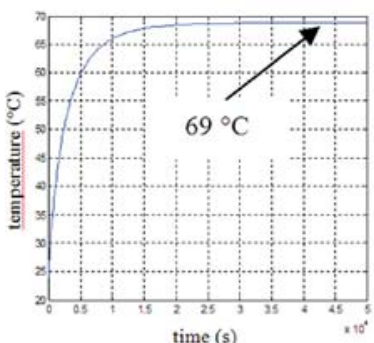

a)

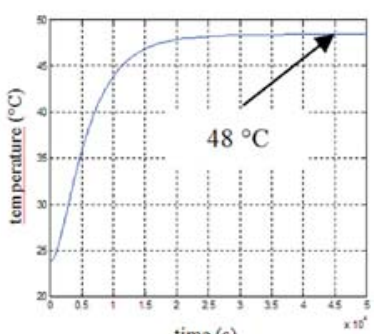

b)
Fig. 22 The temperature curves of motor $C$ for rated load $2 \mathrm{~kW}:$ a) stator winding temperature, $U_{s p h}=230 \mathrm{~V}, I_{a s}=3.2 \mathrm{~A}$,

b) PM temperature, $U_{s p h}=230 \mathrm{~V}, I_{a s}=3.2 \mathrm{~A}$

The Fig. 22 shows that motor $\mathrm{C}$ works at rated stator voltage and rated load in safe temperature limits and there is no risk of its thermal damage.

\section{Conclusion}

The effect of different PM material on PMSM properties was investigated. The experiments and simulations showed how important it is to choose the right ratio of the $U_{s p h} / E_{P M}$ in PMSM operation. Very low and also very high ratios cause higher stator current which results in dangerous thermal conditions in PMSM. The simulations also showed that the replacement of the NdFeB by ferrites in the original configuration causes very poor properties of PMSM and a new design of PMSM is required. Although the ferrites do not have so excellent properties as $\mathrm{NdFeB}$, it is possible to design PMSM with a very good efficiency if the design is proper. The progress in ferrite properties is expected in the future and then they could be employed in PMSM designs more often also due to their lower costs. The investigation confirms the fact that a PMSM design is a complex process. Many aspects have to be taken into account if the PMSM with excellent properties is required.

\section{Acknowledgment}

This work was supported by the R\&D operational program Centre of excellence of power electronics systems and materials for their components II. No. OPVaV-2009/2.1/02-SORO, ITMS 26220120046 funded by European regional development fund (ERDF). 


\section{COMMNICOIIONS}

\section{References}

[1] http://www.hitachi-metals.co.jp/e/prod/prod03/p03_10.html

[2] http://www.magsy.cz

[3] LIANG FANG, LEE, B.H.; LEE, J.J.; KIM, H.J.; JUNG-PYO Hong: Study on High-Efficiency Characteristics of Interior Permanent Magnet Synchronous Motor with Different Magnet Material, Electrical Machines and Systems, ICEMS 2009

[4] RICHTER, E., NEUMANN, T.: Line Start Permanent Magnet Motors with Different Material, IEEE Trans. Magnetics, vol. 20, p. 1762-1764, ISSN: 0018-9464

[5] CHAUDHARI, B. N., FERNANDES, B. G.: Synchronous Motor Using Ferrite Magnets for General Purpose Energy Efficient Drive, TENCON 99, 1999, ISBN: 0-7803-5739-6

[6] SEKERAK, P., HRABOVCOVA, V., RAFAJDUS, P., KALAMEN, L.: Interior Permanent Magnet Synchronous Motor Parameters Identification, ISEM 2010, Prague, 2010, AFC, pp.: 107-116, 978-80-01-04621-0

[7] PYRHONEN, J., JOKINEN, T., HRABOVCOVA, V.: Design of Rotating Electrical Machines, Wiley, 2008, ISBN: 978-0-470-69516-6

[8] RUOHO, S., KOLEHMAINEN, J., IKAHEINEN, J., ARKKIO, A.: Interpedance of Demagnetization, Loading and Temperature Rise in a permanent-Magnet Synchronous Machine, IEEE Trans Magnetics, vol. 46, No. 3, March 2010

[9] RAFAJduS, P., SEKERAK, P., KAlAMEN, L., HRABOVCOVA, V., CHEN, H.: Static and Dynamic Analysis of Linear Switched Reluctance Machine, Communications - Scientific Letters of the University of Zilina, vol. 6, No. 4, 2011. 